\title{
Improving intellectual access in temporary exhibitions for sight loss visitors through co-creation and co-assessment
}

\section{Introduction}

The research project conveyed in this article explores how to inclusively design and curate a non-permanent design exhibition in a large regional gallery (the National Centre for Craft and Design, UK), focusing on enhanced intellectual access for blind and partially sighted visitors. Intellectual access is defined in this research as making it easy for visitors to grasp the content of an exhibition, even if the recipient has no previous knowledge of the subject. The context and rationale for the research, and how the author has attempted to collaborate with various stakeholders and tailor the cocreation research to the specific needs of the blind and partially sighted participants are imparted. The resulting multi-sensory non-permanent exhibition is also described and how it was tested.

\section{Context: Blind and partially sighted people often visit UK exhibitions}

People living with sight loss often visit visual art exhibitions (RNIB, 2003) and museums in the UK (Salgado and Kellokoski, 2005; Mesquita and Carneiro, 2016). Academics and arts professionals continue to argue publically funded museums and galleries need to rethink their notions of accessibility for this group (Cachia, 2013; Hyder and Tissot, 2013; Walters, 2009). Sight loss affects people of all ages, but older people are increasingly likely to experience it (RNIB, 2016). Since 2005 this age group has been the fastest growing visitor group (65-74 years) to UK museums and galleries (DCMS, 2016). The majority has partial sight or have lived with vision, so have a visual memory and engage with visual culture (Access Economics, 2009). There are approximately two million people in the UK who are registered blind or partially sighted (RNIB, 2016). There are two main categories of vision impairment: Partially sighted people will have one or a more of the following:

- Reduced ability to see objects clearly at a distance.

- Reduced ability to see objects clearly at a close distance.

- Loss of vision in central or peripheral field. 
Blind people have a severe vision impairment requiring them to use braille and other tactile and audio materials, and will be those with:

- No vision.

- Only the ability to perceive light and dark.

- $\quad$ Severely reduced visual acuity (RNIB, 2016).

The education and access officers in large UK museums and galleries normally attend to accessibility matters (Cachia, 2013; Candlin, 2008) but in smaller regional venues this responsibility is generally unspecified (Partington-Sollinger and Morgan, 2011). To address the Equalities Act 2010 UK museums and galleries are trying to increase accessibility in two key areas: the venue and the interpretation of exhibits (Mesquita and Carneiro, 2016). An increasing number of large national venues are providing access to permanent exhibits for people with sight loss via pre-booked visits and guided tours including touch tours (Krantz, 2013; Hoyt, 2013). In addition, several museums are beginning to incorporate open-access tactile and/or auditory facilities within a minor number of their permanent collections (Ginley, 2013; Museums Association, 2017). These types of multi-sensory exhibits tend to be small additions to the main collections rather than a central feature, and campaigners often comment that this provision is inadequate (RNIB, 2003; Hirose, 2013).

There is acknowledgement that a key barrier to provision of intellectual access for sight loss visitors is curators not sufficiently considering inclusive design and curatorship principles at the start of the exhibition process (Ginley, 2013; Hirose, 2013). It is even more problematic for regional venues due to the lack of resources and awareness of such issues (Partington-Sollinger and Morgan, 2011). This is significant as people with sight loss in the UK favour these venues over larger national institutions because they are close to home and less crowded and intimidating (RNIB, 2003).

To date there has been a limited response to the development of inclusively designed and curated exhibitions by regional galleries and museums in the UK (Partington-Sollinger and Morgan, 2011). Interest in intellectual access for this group has increased over the past two decades, but research in this field is still scarce (Mesquita and Carneiro, 2016). Inclusive design research into how regional museums and galleries can cost effectively design and curate an exhibition that brings outstanding intellectual access to visitors with sight loss is rare (Cachia, 2013; Candlin, 2008). 


\section{Partner: The National Centre for Craft \& Design}

Following extensive discussions with the National Centre for Craft \& Design’s (NCCD) senior management concerning their accessibility provision, the author collaborated with them to improve intellectual access for visitors with sight loss to their exhibitions (Stage 1: January 2016-July 2017). People with sight loss became the focus because $63 \%$ of their visitors are over 65 years old (Chick, 2016a). NCCD have at least five non-permanent exhibitions in the Main Gallery each year and another 15 exhibitions in their smaller gallery spaces, with approximately 150,000 people benefitted from their activities per annum (Chick, 2016b).

For the key collaborator of this research project Bryony Windsor (Head of Exhibitions, NCCD) the overall goal when planning an exhibition is to create an aesthetically pleasing environment that communicated ideas, develops an understanding of the object displayed and contributes to a meaningful experience (Chick, 2016b). The concept of an exhibition has changed over time, but it is usually understood as a selection of objects put on show for an audience. Roberts (2014) highlights the production of an exhibition is not readily amenable to being divided into a series of clearly defined tasks and describes the process as messy and overlapping.

The author worked closely with NCCD staff in order to gain an appreciation of the workplace culture, and a group was formed with Windsor, two gallery assistants, exhibition designer (Dechelle), five sight loss participants (two blind people with visual memory and three with severe visual impairments) and their companions, and a disability arts consultant (Partington). The sight loss people were all female, as no men volunteered or were recommended to the author. These participants agreed to contribute to creating and assessing the inclusive exhibition.

\section{Research methodology}

This real world, applied research has been framed by a number of co-production principles as well as engaging with the materials of design. This means the research regards the sight loss visitors as active agents and not merely passive recipients of the exhibition curation and design. So the exhibition development was driven by the sight loss participants' knowledge and experience, and was valued on a par with the professionals (Sanders and Stappers, 2008). 
The aim of this research was to improve understanding of the nature and mechanisms of an inclusively designed and curated non-permanent exhibition in a regional venue. Multiple qualitative research techniques and components of coproduction (co-creation and co-assessment) were used to engage identified stakeholders: curator, gallery assistants, exhibition designer, sight loss visitors, disability arts experts, and national organisations.

\section{Literature review}

The author undertook a review of peer-reviewed journals, grey literature and websites (published in English between 1995 and 2016) to identify practical insights and guidance on how to design and curate an inclusive exhibition for visitors with sight loss. Database searches were made for publications using a combination of the following words: ‘accessibility’, ‘exhibition’, 'guidance’, 'guidelines’, 'inclusive’, ‘design’, 'museum', 'gallery'. The search was undertaken using the University of Lincoln EBSCO Discovery Service, which incorporates a wide array of academic databases. In addition, a search for suitable grey literature and website text via an internet search using a Google search engine. Individual searches using the combination of terms above were used to recover reports, websites and documents. The first four pages of a search were scanned for relevant documents.

\section{Working guidance document}

Most of the useful inclusive exhibition guidance identified was grey literature written and published by large museums and associations (NMS, 2002; Smithsonian Institution, 1996, 2001, 2011; Tyne \& Wear Archives and Museums, 2010). In collaboration with Windsor the author developed a working guidance document, which was relevant to a regional venue with limited resources. The majority of identified guidance was aimed at the development of permanent exhibitions in large venues. This meant the author had to adapt this information to that of a regional venue and non-permanent exhibition. This working document was continually up-dated during this project to incorporate new insights. 


\section{Practice-led research: The non-permanent exhibition}

The working guidance document was used as the platform for exploring how to effectively design and curate the next Main Gallery exhibition to be intellectually accessible for visitors with sight loss. First the author had to raise funding to support the exhibition content, public engagement, and research activities. The NCCD partnership meant the research project had to work within their resources and exhibition timetable. This produced an ideal framework for understanding how an inclusively designed and curated non-permanent exhibition could be realistically developed in a regional venue.

The exhibition was titled '3D Printing: The Good, The Bad, and The Beautiful' and explored how citizens, designers, and other professions are using additive manufacture, and its bringing about social, organisational, and economic shifts. This topic was interpreted by the author through key themes and exhibits, text panels, audio interpretations, public talks, and an education program. The exhibition was open from 27 January to 23 April 2017.

\section{Multi method research}

A multi-method approach was used to bring rigorous understanding to this research, as multi-method analysis increases the possibility of getting varied and extensive results.

\section{Participant observation}

Participant observation was used as a way to increase the validity of the research, as the objective was for the observations to help the author better understand the context and phenomenon under study. Observation was used alongside interviewing, document analysis, and other qualitative methods as discussed below (DeWalt and DeWalt, 2002). The objective was to understand how NCCD curated and managed their temporary exhibitions. In addition, to acquiring insights into effective co-production approaches with sight loss participants and what they deemed important in the design and curation of an exhibition (Schensul et al., 1999: 91). The author also observed exhibition visitors including sight loss and carers/companions groups (organised with the RNIB and SENSE) in the gallery. Exhibition visitors were also videoed and the footage reviewed by the author.

\section{Semi-structured interviews}

Semi-structured interviews were conducted twice with Windsor, two gallery assistants and one exhibition designer. The first interview was concerned with their existing non- 
permanent exhibition curatorial and design practices, and the second focused upon the interviewee's reflections on the inclusive design and curatorial process and completed exhibition. These interviews occurred face-to-face at the NCCD venue, lasted approximately forty-six minutes, and were audio recorded.

Semi-structured interviews were also conducted with four sight loss participants (two blind females with a visual memory and two partially sighted females). They are regular visitors to galleries and museums, and were asked about their experiences of visiting exhibitions. Two of the four interviewees (one blind and the other partially sighted) were interviewed a second time on their experience as co-creation participants and the completed exhibition. One interview took place at the NCCD venue and the other at the interviewee's home, with each being audio recorded and lasted approximately forty minutes.

An additional two semi-structured interviews occurred with two new partially sighted exhibition visitors about their experiences as visitors to the completed exhibition. To ensure that the same aspects were covered, the author used a similar structure for all interviews. A consistent list of questions provided a framework for discussion to elicit comparable material without restricting novel input from each interviewee. These participants were contacted and recruited through the NCCD and the regional Royal National Institute for Blind People (RNIB). The gallery assistants were also provided with these interview questions and trained in interview techniques, so they could collect additional data from visitors when the opportunity arose. These discussions were not audio recorded, so the assistants wrote down their recollections following each discussion. A visitor survey and socio-economic profiles were also produced.

\section{Co-creation sessions}

Co-creation is viewed by the author in a transdisciplinary way starting from a tangible, real-world problem, with the resulting solutions being devised in collaboration with multiple stakeholders (Sanders and Strappers, 2008; Bovaird and Loeffler 2014). An aim of the partnership with NCCD was to capacity build throughout the research. The most effective way to work towards this goal was for the author and NCCD curatorial staff to fully collaborate. In addition, to working closely with an exhibition designer, relevant national organisations and people living with sight loss.

The aim of the co-creation sessions was to highlight relevant questions and issues that otherwise could have been neglected by the author and NCCD (Bovaird and Loeffler 2014). The concept of 'contact zones' was adopted to develop 'more 
democratically negotiated' relationships and knowledge exchanges (Clifford 1997: 124), rather than the 'user' participants gaining autonomous power over the solutions. Co-creation activities with sight loss individuals posed challenges due to differences in their mutual experiences and many well-established co-creation tools were not considered appropriate. The methods frequently draw upon exactly those skills that people living with sight loss have problems with, as the tools rely on visual communications. So the author adopted a highly iterative approach towards adjusting the techniques for the participants, and was guided by the 'two Rs' (responsiveness and representation) and 'two Is' (inclusiveness and iteration) for creating and maintaining constructive relationships with participants (Barbera et al., 2016).

Over a five months period three co-creation sessions were hosted, with five participants at each workshop. The author and Windsor attended all sessions, and every effort was made to accommodate all participants. The RNIB and sight loss participants and companions were not paid for their involvement, but all expenses were funded, such as transport and refreshments. The workshops were all held at the NCCD building to provide continuity. The overarching question posed in the co-creation workshops was: How to design and curate an outstanding non-permanent exhibition in the NCCD Main Gallery, prioritising intellectual access for blind and partially sighted visitors?

It transpired there is insufficient guidance and research on how to effectively facilitate a co-creation process with sight loss participants (Taxén, 2004; Hendriksa et al., 2015), so the author had to cultivate practices that fostered intellectual and social access for such participants. The author first consulted Partington, and when trust was built the other participants suggested improvements to the co-creation process. Before these workshops sighted participants and other NCCD staff were trained by Partington in how to engage with sight loss visitors, as there was a need for thoughtful and empathetic behaviour. This training proved invaluable to building trust during the co- creation and co-assessment sessions. Topics covered included understanding the attitudes that can be a barrier for blind and partially sighted people engaging with sighted people as well as accessing a museum or gallery; the background to sight loss; facts and figures; and the dispelled of myths around sight loss. 
Co-creation is generally based on tools and techniques that rely on visual communications (Sanders and Strappers, 2008) and was still partly the case in the three sessions. As two of the participants were blind, and the remainder had degrees of sight loss, it meant all visual imagery was enlarged and text adhered to the RNIB's accessibility publication guidelines. The author, Windsor, and Partington facilitated one session each, and encouraged open dialogue. In the first two sessions the participants used a large whiteboard to write down ideas, which were then typed up and projected large onto a screen. The text was then sent to the laptops of the blind participants, who used audio text recognition software.

The participants were encouraged to generate as many ideas as possible. Each person described their ideas to the group. The others were encouraged to share their thoughts on the ideas and to build on them. As constructive relationships occurred participants more effectively verbalised their design and curatorial ideas and concepts, and how to improve the co-creation process. This resulted in printed sheets being mounted onto thin card to aid close up viewing. Small- scale models of design concepts were produced so they could be easily handled on a table for discussion and evaluation.

\section{First co-creation session}

The agenda for the first workshop was the key topics covered in the working document, and deciding upon a rationale for the exhibition design and curation. It became evident that this guidance framework was an effective approach as the sight loss participants illustrated the consequences to them of ill-considered practices. The group became increasingly knowledgeable about these visitors’ requirements leading to novel improvements to the working guidance. It became apparent the overall exhibition design and curatorship would need to address the bias towards visual culture to experience the exhibition. This led to the decision the core mission for the exhibition was to achieve intellectual access through inclusive, multi-sensory communications. Participants identified the following exhibition milestones:

- Multi-sensory exhibition that was inclusive to all visitors.

- Gallery way-finding solution.

- Interpretive audio information.

- Cost effective audio equipment.

- Inclusively designed wall panels and object labels.

- Large-print and Braille brochures.

- Gallery assistant visitor assistance and interpretation. 


\section{Second co-creation session}

Realising the exhibition design in a short space of time was one of the main challenges and so it was decided to have another co-creation session (10:30am - 16:00) involving the same participants. This session began by brainstorming (van Westen and van Dijk, 2015) the multi-sensory exhibition design concepts linking them to the curatorial topic themes and exhibits. Following this session the author, Windsor and Dechelle iteratively consolidated and developed the resulting inclusive curatorial and design insights and concepts from the first session.

Through the co-creation sessions it was deemed important to have touching objects 3D printed from different materials to demonstrate diverse forms and textures, as it was an exhibition about additive manufacture. This variety would be of interest to all visitors, but especially to blind people, as a materials characteristics was also a selection factor. A priority for the author was the development of a design that clearly demonstrated this was a multi-sensory exhibition to reflect the key principles emerging from the co-creation sessions. In response Dechelle designed the multi-sensory desk idea, which was reviewed in the final co-creation session.

\section{Final co-creation session}

The ideation stage was carried out during the final co-creation session, throughout the final design and curation stages, as well as the co-assessment sessions. 'Low fidelity prototyping' and 'bodystorming' (McDermott, et al., 2015) approaches were used to make ideas tangible, to learn through making, and to get key feedback quickly on design concepts from the sight loss participants. Bodystorming requires the physical setting up of a situation with objects and people, in this case the exhibition, with the manner in which the participants act and interact to the physical environment being observed and discussed. The drawings of the exhibition designs (supplied by Dechelle, the exhibition designer on the team) were used to aid discussions with the author, NCCD team and with partially sighted participants. With blind participants the design concepts were verbally described and low fidelity prototypes of the desk, and some of the multi-sensory content such as audio descriptors, trim phone and touching objects were used to explore the concept solutions in the final co-creation session (see Figure 1).

\section{Co-creation dynamics}

The focus of the collaboration with the sight loss participants was on the inclusive exhibition design and curation, not on developing the exhibition narrative or selection 
of the exhibits. The author developed the exhibition content and structure in collaboration with Windsor, and both selected the exhibiting objects. Nevertheless, they were steered by the co-creation sessions and the working guidance document when creating the exhibition text and selecting exhibits. For example exhibits were identified that could be handled or replicas produced. Windsor and the author liaised with exhibitors and lenders to acquire touching objects, as well as organise the design and $3 \mathrm{D}$ printing of others, resulting in touching objects in a variety of materials and textured for the multi-sensory desks.

There were times during the co-creation sessions when Windsor and the author offered their experience to ensure the design of the exhibition was aesthetically fitting. An example was the typeface Arial was proposed by some of the participants as the most inclusive typeface for the exhibition graphics but because Windsor and the author did not think this typeface was suitable, another san serif typeface was chosen, which caused some tension in the group. It was therefore agreed to test the readability and legibility of six exhibition wall panels of different typographic designs including Arial. The wall panels varied in typeface, type size, line and word spacing, background colour and whether there was a borderline around the panel.

\section{Multi-method triangulation}

The author aimed to bring dependability to the evaluation process by using multi- method triangulation and an adapted iterative stepwise replication approach for qualitative data. Kopinak (1999: 171) indicated that the use of multiple qualitative methods provides for more detailed and multi-layered information about the phenomenon under study, and to determine if there is a convergence and hence, increased validity in the research findings. The adapted 'stepwise replication approach' (Chilisa and Preece, 2005) involved the author and Windsor regularly evaluating the data and reflecting upon it by discussing and addressing any inconsistences, as well as consulting Dechelle and Partington. This evaluation process occurred at least every two weeks.

This evaluation approach continued following the exhibition opening, alongside the second round of interviews, observations, and co-assessment sessions in the Main Gallery. The evaluation of the exhibition was driven by the central question: Does the interpretation provision significantly aid an understanding of the exhibition subject matter and exhibits for blind and partially sighted visitors? The interviews and co- 
assessment sessions allowed the author to have in-depth conversations with the curatorial staff, sight loss participants and visitors about their exhibition experience, in a manner that they may not have done unprompted.

The use of multiple methods of data collection and the triangulation of this data provided insights into the effectiveness of each component of the exhibition in providing intellectual access. The findings from this study help to not only document visitors and participants opinions, but also can be carried forward and apply to future exhibitions.

\section{Co-assessment sessions}

Two co-creation participants and two new sight loss visitors agreed to co-assess the completed exhibition. The bodystorming approach was used, so the participants first experienced the exhibition on their own (with and without a companion), and then with a gallery assistant on a one-to-one tour (see Figure 2). Finally they toured the exhibition again with the author and Windsor to carry out the semi-structured interview and critique the exhibition with regards to intellectual access.

The co-assessment sessions did result in the development of new and innovative intellectual access solutions that addressed issues such as people with low vision needing to be within $75 \mathrm{~mm}$ of a label to read it (Smithsonian Institution, 2011:25). The new resolution was to design the object labels so they could be picked up from a plinth by a visitor for close up reading. The top label would not be fixed to a plinth, but accompanied by a shadow copy underneath which was attached. This solution was not in any guidance documentation reviewed and is an extremely cost effective inclusive design resolution for regional non-permanent exhibitions.

\section{Final exhibition: Inclusively designed and curated components}

\section{Gallery colours}

Black on white, and black on yellow was the colour scheme chosen for the exhibition identity because they are regarded as the clearest combination for creating a welldefined contrast between text and background for partially sighted people (NMS, 2002; RNIB, 2003). These colours were used to distinguish the walls, floor, and plinths from each other, resulting in the floor colour tonally contrasting with the walls and plinths (see Figure 3).

Visitors with a severe visual impairment found it difficult to identify a white plinth if too close to a white gallery wall, but the tonal contrast between the plinth and 
the dark grey floor aided identification. The wall panels with a white background on the white gallery wall were also difficult to locate for these visitors too. This was because if the colour hues for such exhibition components were similar (less than $70 \%$ contrast) they can blend together for people with certain types of visual impairment (Smithsonian Institution, 2011).

In response the author developed a 'Creative Lab' zone in the entrance of the Main Gallery to test different wall panel and object label graphic designs, as well as colours on plinths and desks (see Figure 4). Visitors were asked to identify with a small coloured sticker the designs they found the most legible and easy to read on a white wall. These stickers were recorded and removed each day over a two month period by the gallery assistants. It was found that placing a black thin line border on a wall panel (even when the background was white) aided visitors. A contrasting background colour to the white wall was also deemed more accessible in identifying a panel for partially sighted visitors.

\section{Multi-sensory desks}

A multi-sensory desk (containing handling objects, object label(s), and magnifier) accompanied each exhibit (displayed on a plinth or freestanding), so the visitor could relate the desk's content to the exhibit. The aim was to provide intellectual access to each exhibit for all visitors. A trim phone (containing the audio descriptors of particular exhibits and wall text readings) was fixed to the lower right-hand side on eight of the 12 desk tops. The desks were $700 \mathrm{~mm}$ high because the guidance consensus was a wide range of visitors can reach over to handle an object at this height, including wheelchair visitors.

Three MDF disks were designed to indicate whether an exhibit could be handled or not, and if there was audio provision (see Figure 5). A trim phone (of contrasting colour to the desks) was used as the hand-set curly lead provided flexibility, so visitors in wheelchairs or are tall could comfortably listen to the audio. The tactile objects on each desk were selected or created to provide a coherent explanation of the associated exhibit (see Figure 6). A demonstration desk was placed at the gallery entrance so a gallery assistant could explain the desk’s function.

The multi-sensory desk concept was deemed a successful innovation by visitors and the curatorial team as they identified the desks enhanced intellectual access for all visitors. Typical feedback was: 'the interactive table is brilliant for kids. Well done' (sighted respondent 32); 'I loved the texture of the fabric sample' 
[Nervous Systems 3D printed dress sample] (blind questionnaire respondent 15); and 'this is inspirational. Loved being able to touch the objects' (partially sighted respondent 46). Nevertheless, visitor feedback did indicate further research into how to effectively assist sight loss visitors to understand the exhibits through a multisensory approach is required. A conversation between a gallery assistant and the mother of a blind teenage daughter highlights this need for further research:

'I really liked the exhibition and my daughter had a good time visiting but I want to leave you with some constructive feedback from us. Firstly, she found the exhibition quite confusing as there was too much [handling objects] on the touch tables'

(sighted respondent 4).

The blind participants also found some of the handling objects 'cold', 'to plastic', 'to lightweight' and 'quite an unpleasant experience' because they did not truly represent the materiality of the original exhibit (blind respondents 2 and 4). Further research into the required haptic qualities of an effective touching object is also required. This includes finding solutions to weighting additive manufactured replica touching objects so they more truly replicate a heavy exhibit.

\section{Way-finding path}

A way-finding path to the multi-sensory desks was laid in the gallery using two types of yellow ground surface mounted tactile (blister and horizontal) indicator paving (350 x 263mm), and secured with double-sided carpet tape. This paving replicates those used to indicate to blind people to stop at a road crossing or to proceed forward. The yellow paving contrasted with the gallery’s dark grey concrete floor so clearly delineated a route for partially sighted visitors (see Figure 7).

Blind visitors, especially those under the age of twenty-five years, found using the path a liberating experience because they felt confident to follow the path unaided for at least sections of the route, as this visitor indicated: 'Clear distinct path to follow' (blind respondent 12). Sighted visitors identified what the textured tiles were and understood what this design was trying to achieve. Unintentionally the path became the inclusive design symbol of the exhibition to sighted visitors. Nevertheless, a notable

number of blind visitors (all over the age of 65 years old) were confused or irritated by the path and layout so did not find it useful: 'I work for SENSE and think ... floor could be a trip hazard and many people will not be guided by floor tiles and [will] find them distracting' (sighted respondent 25). A significant number of elderly visitors also found the path painful and an unstable surface to walk on due to arthritic feet: 
'I am old and have arthritis, it is really hard to take my waking aid around with me as the floor [the tactile way-finder path] gets in the way so it is hard to push. I can see why you did it, as it is good for the visually impaired, but it makes it difficult for me. I wear insoles in my shoes, and they keep getting moved about when I stand on the floor’ (partially sighted respondent 2).

The author also observed a small number of visitors were hesitant to walk over or on the tactile paving. This behaviour was explained by their carers as the contrasting colours of the bright yellow path and the dark grey floor causing a depth perception issue for some people with Down Syndrome. They often have eye and vision issues and in this situation resulted in the path being perceived as a shallow trench or a short wall.

A way-finding pathway guiding a sight loss visitors to exhibits and the desks was deemed to have strong merit by visitors and research participants, but other pathway solution need to be explored regarding alternative materials, tactile surfaces and colour contrasts (between the path and base floor). Practically the bright yellow flooring will not be suitable for all non-permanent exhibition designs.

\section{Audio provision}

Audio support was considered essential in this exhibition by the sight loss participants. Audio descriptors for key exhibits were written by the author in accordance with common practice, but with contextual detail added to broaden the information and appeal (Fryer, 2016; Maszerowska et al., 2014). Audio delivery posed a problem because of the restricted space between exhibits, prohibiting any kind of 'zoned' loudspeaker system due to the possibility of interference. Instead oldfashioned trim-phones were adapted to play back digital files, which meant that eight could be placed in close proximity with no danger of interference.

Gauging an appropriate sound level for the audio was problematic as the level had to accommodate visitors with a hearing impairment but within safe levels for children. This particular issue requires further exploration and testing because there were comments the audio was too quiet made by visitors (all over 65 years old). Three sight loss visitors also requested the audio could be a group experience: 'If you come with another person, they can’t listen with you. Maybe two phones’ (blind respondent 3).

The selection or commissioning of exhibits that created a sound was not considered by the author and Windsor, but feedback suggests this would have been a 
positive addition. Nevertheless, on the recommendation of the sight loss participants the exhibition did have demonstration 3D printers, so visitors could hear and feel the vibration of the printers by placing their hands on the table: 'Loved the demonstration printer as I could hear it and feel it printing' (blind respondent 3).

\section{Exhibits on plinths}

The plinths were arranged in the gallery to allow the exhibits to be viewed close up from at least three sides. Exhibits were also arranged to avoid visual clutter and not placed against complex backgrounds, as some sight loss people have issues with foreground-background discrimination (Smithsonian Institution, 2011). Enlarged images of small and detailed exhibits were displayed on the gallery walls and could be viewed close up, as a direct result of the co-creation sessions.

The curators persuaded approximately $30 \%$ of exhibitors and lenders to allow their exhibits to be touched in the exhibition, but not handled. Various reasons were provided such as additional insurance costs and concerns over work being damaged. The blind participants and visitors were usually annoyed they could not handle all exhibits, as one remarked:

'I have been blind for over 20 years, so handle objects gently so I can understand them. I don't damage things as I have had lots of practice. I would have a richer experience at a museum and gallery and understanding of an exhibit better if I could touch it' (blind respondent 1).

Exhibitors and lenders who visited the exhibition often provided retrospective permission for their exhibits to be touched, as they more clearly understood the inclusive aims of the exhibition and the research project. With assistants permanently present in the gallery a decision was made by NCCD to offer accompanied handling for most objects to sight loss visitors. Further research into overcoming the barriers to permission being granted for exhibits to be touched in non-permanent exhibitions is required.

\section{Exhibition graphics}

The wall panels and object labels were designed to be a simple layout, with wellspaced aligned left paragraphs, clear hierarchy of title and main message, as well as consistent line spacing (see Figure 8), as this was the consistent guidance provided by all the inclusive graphic design guidelines. Futura font body text was 36pt for the panels and 16pt for the object labels because the typeface was acceptable to all cocreation participants, as well as acknowledged in various guidance (NMS, 2002; 
Smithsonian Institution, 2001; Tyne \& Wear Archives and Museums, 2010). The most positive feedback on the exhibition was how easy it was for visitors to read these panels and labels, and that visitors could get very close to them for reading.

\section{Lighting}

The co-creation workshops ascertained consistent lighting levels that illumination objects and labels is particularly important, as well as avoiding shadows falling on exhibits and wall panels. Light reflecting on exhibit cases was also minimised by using new matt Perspex with no scratches, but this surface was still problematic for a small number of visitors due to reflections.

\section{Gallery assistants}

The gallery assistants grew confident to host sight loss visitors due to the training and the ongoing experience. Providing responsive tours and being available in the gallery was highly valued by all visitors, but especially those with sight loss. The assistants became adept at overcoming any communication shortcoming in explaining to sight loss visitors the exhibition content:

'The main thing I will take away is just an awareness of the visitors' needs and I'm very interested personally in audience development and how audiences interact with exhibitions. I will always be more aware of the fact that they may have different needs and it's my job to, kind of, tailor the visit and the experience around those needs. So that's the biggest thing that I've learnt' (Gallery assistant 1).

\section{Conclusion}

This research has improved upon existing inclusive exhibition design guidance by creating new and novel solutions that bring enhanced intellectual access to sight loss visitors. The resulting improved inclusive exhibition guidance and insights were a consequence of the collaborative nature of the research and the involvement of sight loss participants, an exhibition curator (Windsor) and exhibition designer (Dechelle). Nevertheless, working with blind participants in co-creation activities has been a challenge due to the common methods and tools being driven by visual communications. Existing co-creation approaches can be modified for partially sighted participants but not for the blind, apart from when making and handling objects and audio solutions. 
On reflection even though the co-creation experiences were undoubtedly rich and dense, there are lessons to be learnt on what to avoid in future research. Most importantly, seemingly minor issues can be a barrier to sight loss participants’ engaging effectively in co-creation sessions, such as distracting background noise, or participants not speaking clearly and stating their name. This means that co-creation sessions with sight loss participants need to be meticulously planned, including providing materials in advance, selecting an appropriate room with good lighting and facilities, and activities will be more time consuming.

\section{Acknowledgements}

The author would like to acknowledge the contribution of the co-creation and coassessment participants, NCCD gallery assistants, Midlands regional RNIB and SENSE participants, exhibition visitors, Arnaud Dechelle, Kevin Hallsworth, Zoe Partington, Colin Webb, and Bryony Windsor.

\section{Disclosure statement}

No potential conflict of interest was reported by the author.

\section{Funding}

This research was funded by the Arts Council England, Grants for the Arts [GFTA-00024769] and The Big Lottery, DRILL fund [FTRND12016\100056]. 


\section{References}

Access Economics. 2009. Future Sight Loss UK. London: RNIB.

Barbera, C., M. Sicilia, and I. Steccolini. 2016. "What Mr. Rossi Wants in Participatory Budgeting: Two R's (Responsiveness and Representation) and Two I's (Inclusiveness and Interaction).” International Journal of Public Administration. 39(13): 1088-1100.

Bovaird, T., and E. Loeffler. 2014. Bringing the Power of the Citizen into Local Public Services: An Evidence Review: Briefing Note for Welsh Government. University of Birmingham and Inlogov.

Cachia, A. 2013. “Talking Blind: Disability, Access, and the Discursive.” Disability Studies Quarterly. 33(3).

Candlin, F. 2008. “Touch, and the Limits of the Rational Museum or Can Matter Think?” The Senses and Society. 3(3): 277-292.

Chilisa, B., and, J. Preece. 2005. African Perspective in Adult Learning: Research Methods for Adult Educators. Hamburg, German: UNESCO Institute of Education.

Chick, A. 2016a. Semi-structured interview with Claire Edwards, Director, NCCD on 2 December 2016.

Chick, A. 2016b. Semi-structured interview with Bryony Windsor, Head of Exhibitions, NCCD on 21 December 2016.

Clifford, J. 1997. Routes: Travel and Translation in the Late Twentieth Century. Cambridge, MA: Harvard University Press.

DCMS. 2016. Taking Part 2015/16 Quarter 1 Statistical Release. London: DCMS. DeWalt, K., and DeWalt, B. 2002. Participant Observation: A Guide for Fieldworkers.

Walnut Creek, CA: AltaMira Press.

Fryer, L. 2016. An Introduction to Audio Description: A Practical Guide. London: Routledge.

Ginley, B. 2013. “Museums: A Whole New World for Visually Impaired People.” Disability Studies Quarterly. 33(3).

Hendriksen, N., K. Slegersb, and P. Duysburghc. 2015. “Codesign With People Living With Cognitive or Sensory Impairments: A Case For Method Stories and Uniqueness.” CoDesign. 11(1): 70-82.

Hirose, K. 2013. "Research on Methods of 'Touching the World' - The Aim of the Exhibit Area of Tactile Learning in Japan’s National Museum of Ethnology.” Disability Studies Quarterly. 33(3).

Hoyt, O. 2013. "Emphasizing Observation in a Gallery Program for Blind and Low - Vision Visitors: Art Beyond Sight at the Museum of Fine Arts, Houston.” Disability Studies Quarterly. 33(3). 
Hyder, E., and C. Tissot. 2013. “'That’s Definite Discrimination': Practice Under the Umbrella of Inclusion.” Disability \& Society. 28(1): 1-13.

Kopinak, J. 1999. “The Use of Triangulation in a Study of Refugee Well-being.” Quality Quantity. 33(2): 169-183.

Krantz, G. 2013. “Levelling the Participatory Field: the Mind’s Eye Program at the Guggenheim Museum.” Disability Studies Quarterly. 33(3).

McDermott, F., Avram, G., and L. Maye. 2015. Co-Designing Encounters with Digital Cultural Heritage. Material EncounterS with digital Cultural Heritage (meSch) project. Retrieved on 30 October 2016 from: http://mesch-project.eu/co-design/

Maszerowska, A., A. Matamala, and P. Orero. (editors). 2014. Audio Description: New Perspectives Illustrated. Amsterdam: John Benjamins Publishing Company.

Mesquita, S., and M. J. Carneiro. 2016. “Accessibility of European Museums to Visitors with Visual Impairments.” Disability \& Society. 31(3): 373-388.

Museums Association. 2017. Museum Practice. Retrieved 2 February 2017 from: www.museumsassociation.org/museums-practice/your-access-case-studies.

National Museums of Scotland (NMS). 2002. Exhibitions for All: A Practical Guide to Designing Inclusive Exhibitions. Edinburgh: NMS Publishing.

Partington-Sollinge, Z., and A. Morgan. 2011. Shifting Perspectives: Opening Up Museums and Galleries to Blind and Partially Sighted People. London: RNIB.

RNIB. 2016. Key Information and Statistics. Retrieved 10 October 2016 from: http://www.rnib.org.uk/knowledge-and-research-hub/key-information-and-statistics

RNIB. 2003. Museums, Galleries and Heritage Sites: Improving Access for Blind and Partially Sighted People. London: RNIB.

Roberts, T. 2014. “Interpretation Design: An Integrative, Interdisciplinary Practice.” Museum and Society. 12(4): 191-209.

Salgado, M., and A. Kellokoski. 2005. “Äänijäki - Opening Dialogues for Visually Impaired Inclusion in Museums.” Paper presented in CONVIVO workshop

Sanders, E., and P. J. Stappers. 2008. "Co-creation and the New Landscapes of Design.” CoDesign. 4(1): 5-18.

Schensul, S., Schensul, J., and M. LeCompte. 1999. Essential Ethnographic Methods: Observations, Interviews, and Questionnaires (Book 2 in Ethnographer's Toolkit). Walnut Creek, CA: AltaMira Press.

Smithsonian Institution. 1996. Smithsonian Guidelines for Accessible Exhibition Design. Washington, DC: Smithsonian Institution.

Smithsonian Institution. 2001. Smithsonian Guidelines for Accessible Publication Design. Washington, DC: Smithsonian Institution.

Smithsonian Institution.2011. Smithsonian Guidelines for Accessible Design. Washington, DC: Smithsonian Institution. 
Taxén, G. 2004. “Introducing Participatory Design in Museums.” Proceedings of the Eighth Participatory Design Conference - Artful Integration: Interweaving Media, Materials and Practices, edited by Besselaar. P., and A. M. Oostveen. New York: ACM. 204-213.

Tyne \& Wear Archives and Museums. 2010. Wayfinding and Orientation: Accessible Information Guidelines. Tyne \& Wear Archives \& Museums.

Van Westen, R., and D. van Dijk. 2015. D4.2 Good Practices and Methods for Co- creation. RICHES Project. Retrieved 21 October 2016 from: http://resources.riches- project.eu/d4-2good-practices-and-methods-for-co-creation/

Walters, D. 2009. “Approaches in Museums Towards Disability in the United Kingdom and the United States.” Museum Management and Curatorship. 24(1): 29-46. 
Figure 1: Co-creation participants exploring the multi-sensory desk concept.

Figure 2: Co-assessment session in the NCCD gallery.

Figure 3: '3D Printing: The Good, The Bad, and The Beautiful' exhibition, NCCD.

Figure 4: Creative Lab in the Main Gallery.

Figure 5: Multi-sensory desk with MDF disks.

Figure 6: Objects for handling on a multi-sensory desk.

Figure 7: Exhibition way-finding path.

Figure 8: Exhibition graphics. 
